\title{
Cutaneous allodynia is more frequent in chronic migraine, and its presence and severity seems to be more associated with the duration of the disease
}

\author{
A alodinia cutânea é mais frequente na migrânea crônica, mas sua presença e gravidade \\ parecem estar associadas com a duração da doença
}

Mariana Tedeschi Benatto', Lidiane Lima Florencio', Gabriela Ferreira Carvalho', Fabiola Dach², Marcelo Eduardo Bigal ${ }^{3}$, Thaís Cristina Chaves², Débora Bevilaqua-Grossi ${ }^{1,4}$

\begin{abstract}
Objective: To evaluate cutaneous allodynia among patients with chronic and episodic migraine in a tertiary headache clinic. Methods: 80 subjects with episodic migraine and 80 with chronic migraine were assessed in a tertiary hospital. The 12-item Allodynia Symptom Checklist/Brazil questionnaire was applied to classify subjects according to the presence and severity of cutaneous allodynia. Results: Cutaneous allodynia was identified in $81.3 \%$ of the episodic migraine group and $92.5 \%$ of the chronic migraine group ( $p=0.03$ ). No increased association could be attributed to chronic migraine when adjusted by years with disease ( $\mathrm{PR}=1.12 ; 95 \% \mathrm{Cl}=0.99$ to $1.27 ; \mathrm{p}=0.06)$. The groups also did not differ in the severity of allodynia, and severe presentation was the most frequent. Discussion: Both groups seemed to be similarly affected in the cephalic and extracephalic regions, with the same severity. Conclusion: Cutaneous allodynia is more frequent in chronic migraine, and its presence and severity seems to be more associated with the duration of the disease.
\end{abstract}

Keywords: hyperalgesia; migraine disorders.

RESUMO

Objetivo: Avaliar a característica da alodinia cutânea em indivíduos com migrânea crônica e episódica em um hospital terciário. Métodos: 80 sujeitos com migrânea episódica e 80 com migrânea crônica de um hospital terciário foram avaliados. 0 questionário 12 -item Allodynia Symptom Checklist/Brasil foi aplicado e classificou os sujeitos quanto a presença e severidade da alodinia cutânea. Resultados: A alodinia cutânea esteve presente em $81,3 \%$ dos migranosos episódicos e 92,5\% nos crônicos ( $p=0.03$ ). Nenhuma associação pode ser atribuída a migrânea ao ser ajustada pela variável anos com doença ( $\mathrm{PR}=1.12 ; 95 \% \mathrm{IC}=0.99$ para 1.27; $\mathrm{P}=0.06)$. Os grupos não diferiram em relação à severidade da alodinia e a classificação severa foi a mais frequente. Discussão: Ambos os grupos pareceram ser igualmente afetados nas regiões cefálicas e extracefálicas com a mesma severidade. Conclusão: A alodinia cutânea é mais frequente na migrânea crônica, mas a presença e severidade parece estar mais associada com a duração da doença.

Palavras-chave: hiperalgesia; transtornos da enxaqueca.

Migraines affect $10 \%$ of the global population ${ }^{1}$ and start as an episodic disease that can evolve to chronicity. Chronic migraine is characterized by the presence of headache on 15 or more days within a month for more than three months'. On at least eight days, the headache features should be of a migraine headache and the pain possibly relieved by a triptan or ergot derivative ${ }^{3}$. Cutaneous allodynia, a risk factor for chronic migraine ${ }^{4}$, increases the discomfort and disability of patients with acute migraine attacks ${ }^{5}$ and is recognized as a clinical manifestation of central sensitization in migraine patients ${ }^{6}$.

Cutaneous allodynia is defined as the perception of pain or discomfort in response to innocuous thermal (heat or cold) and/or mechanical (static or dynamic) stimuli applied to normal skin ${ }^{6}$. It occurs in approximately $80 \%$ of migraine sufferers,

\footnotetext{
1 Universidade de São Paulo, Faculdade de Medicina de Ribeirão Preto, Departamento de Biomecânica, Medicina e Reabilitação do Aparelho Locomotor, Programa de Pós-Graduação em Reabilitação em Desempenho Funcional, Ribeirão Preto SP, Brasil;

${ }^{2}$ Universidade de São Paulo, Faculdade de Medicina de Ribeirão Preto, Departamento de Neurociências e Ciências do Comportamento, Ribeirão Preto SP, Brasil; ${ }^{3}$ Desenvolvimento Global da Teva Pharmaceutical Industries Ltd.,Filadélfia, EUA ;

«Universidade de São Paulo, Faculdade de Medicina de Ribeirão Preto, Laboratório de Análises da Postura e Movimento Humano (LAPOMH), Ribeirão Preto SP, Brasil. Correspondence: Débora Bevilaqua-Grossi; Av. Bandeirantes, 3900; 14049-900 Ribeirão Preto SP, Brasil; E-mail: deborabg@fmrp.usp.br

Support: São Paulo Research Foundation (FAPESP).

Conflict of interest: There is no conflict of interest to declare.
}

Received 02 May 2016; Received in final form 29 September 2016; Accepted 21 November 2016. 
with a greater prevalence among women ${ }^{7,8,9,10}$. This symptom is a dynamic phenomenon, the intensity of which varies throughout the course of a migraine episode ${ }^{7}$.

Cutaneous allodynia interferes in the effectiveness of abortive therapy with triptans, reducing their effectiveness in total pain relief and in preventing relapse within 24 hours ${ }^{11}$. In order to be effective, triptans must be administered before the presence of cutaneous allodynia ${ }^{12}$. Therefore, identifying the presence of allodynia and educating patients on the particularities of this symptom are essential for adequate treatment.

Among the available methods to identify cutaneous allodynia, the only tool that allows classification of the severity of cutaneous allodynia presentation is the 12-item Allodynia Symptom Checklist (ASC-12) questionnaire ${ }^{7}$. Studies comparing the characteristics of cutaneous allodynia in chronic and episodic migraine sufferers are still scarce and results are conflicting regarding the severity of cutaneous allodynia in both groups. Schwedt et al. ${ }^{13}$ reported differences in the ASC-12 score of migraine sufferers compared to a control group, but no differences were found in the severity of cutaneous allodynia among patients with chronic and episodic migraine. On the other hand, Bigal et al. ${ }^{4}$ verified that cutaneous allodynia is influenced by the frequency of attacks, as it is more prevalent and severe in chronic migraine sufferers than in episodic migraine sufferers.

Thus, the objective of this study was to assess cutaneous allodynia in chronic and episodic migraine sufferers at a tertiary outpatient headache clinic. The hypothesis is that cutaneous allodynia is influenced by the frequency of attacks and therefore, chronic migraine sufferers have a higher frequency and severity of cutaneous allodynia compared to episodic migraineurs.

\section{METHODS}

\section{Participants}

Among of 484 potential patients, 64.25\% were excluded and $2.68 \%$ declined to participate the study, resulting in a final sample of 160 participants (Figure 1). The sample included patients of both genders between the ages of 18 and 55 who had been diagnosed with migraine, according to the third edition of International Classification of Headache, between July 2013 and May 2014. The diagnosis was made by an experienced neurologist in a tertiary hospital during a routine appointment. Standard neurological examinations were performed and neuroimaging was ordered only if necessary. The neurologist checked the information on the frequency and duration of migraine attacks. The absence of systemic comorbidities was confirmed by medical records. Migraine sufferers were allocated to two groups: the episodic migraine group, comprising patients with headache on fewer than 15 days within a month in the last three months; and the chronic migraine group, comprising those affected by headache on 15 days or more within a month in the last three months ${ }^{14}$, and who presented with migraine headache features on at least eight attacks, relieved by a triptan or ergot derivative ${ }^{3}$. Exclusion criteria were: 1) diagnosis of another headache associated with migraine, including medication-overuse headache; 2) diagnosis of fibromyalgia, trigeminal neuralgia and systemic diseases that could lead to a peripheral neuropathy; 3 ) patients with an acute migraine attack. As the protocol of the headache clinic, all patients received individual prescriptions for the use of prophylactic medication. The most

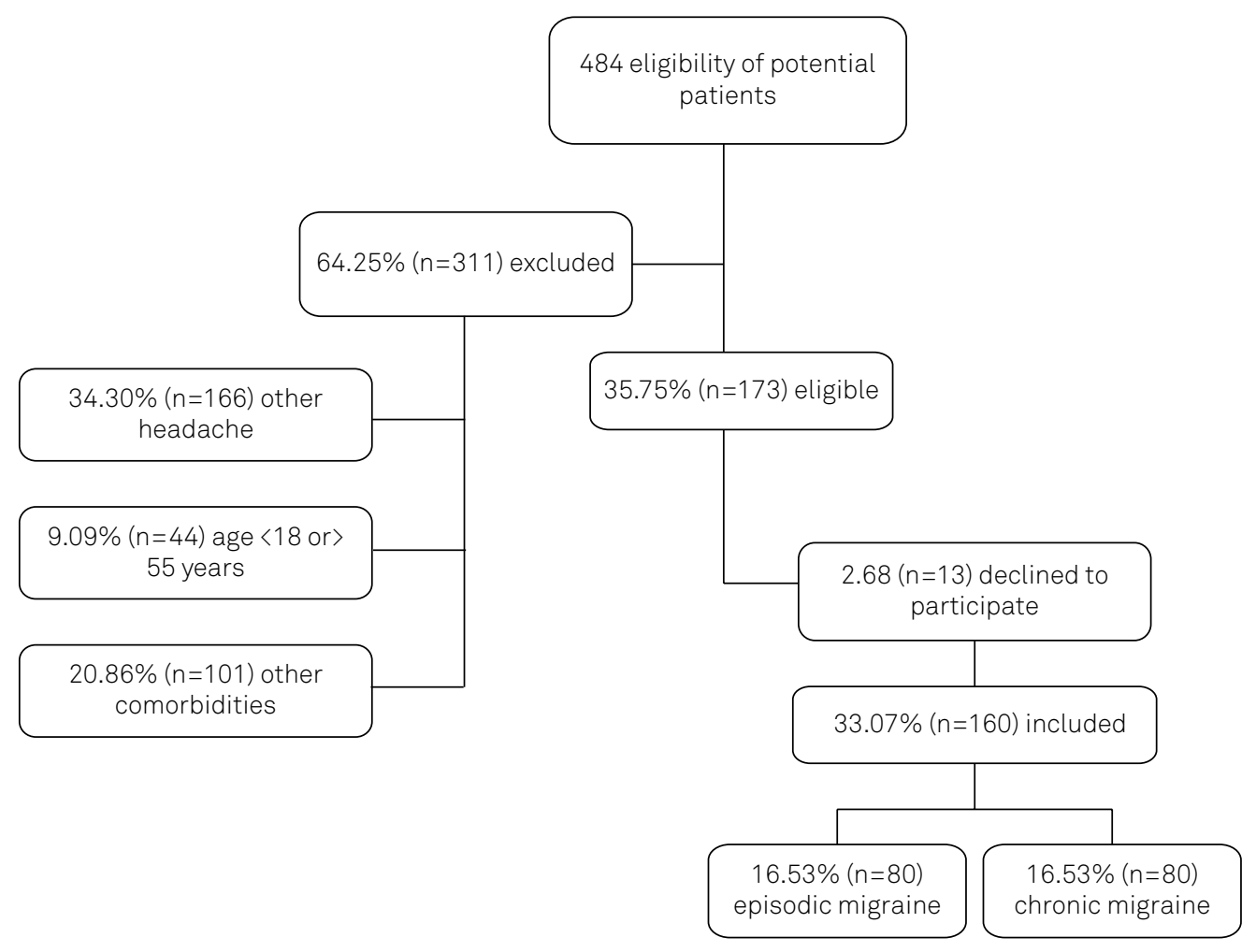

Figure 1. Flowchart of patients. 
prescribed drugs were antidepressants and anticonvulsants, respectively, amitriptyline and topiramate. The most common abortive medications prescribed were triptans, including sumatriptan and naratriptan and all patients received instructions to avoid overuse of analgesics. The study was approved by the local ethics committee (process no. 15580/2012).

A non-blind examiner was in charge of the patient selection: checking all possible patients who met the inclusion criteria and confirming the exclusion criteria in the medical history of the hospital register. Then, the examiner confirmed the criteria by inviting the patient to participate. After acceptance and signing the informed consent, patients were questioned about their migraine characteristics. Years with migraine, the frequency of attacks (days with headache per month) and duration of attacks (hours) was based on self-reports. Then a blind examiner administered the ASC- 12 .

\section{Questionnaire}

The ASC-12 is capable of identifying cutaneous allodynia according to the nature of the stimulus: thermal, mechanical static or mechanical dynamic ${ }^{7}$. It is a self-completion questionnaire and consists of 12 questions regarding discomfort during migraine episodes during everyday activities, such as combing hair, wearing glasses, and taking a showe ${ }^{15}$. Scores range from 0 to 24 and the presence of cutaneous allodynia is attributed to those who score $\geq 3$ points. Classifications of patients according the presence and severity of cutaneous allodynia are: no allodynia ( $0-2$ points), mild allodynia (3-5 points), moderate allodynia (6-8 points) and severe allodynia ( 9 or more points) ${ }^{7}$. Furthermore, based on an exploratory factor analysis and interpretation by the authors, items were grouped into three domains of cutaneous allodynia: thermal domain, measured by the items "taking a shower," "exposure to heat," "exposure to cold," "resting your face or head on a pillow" and "shaving your face"; the mechanical dynamic domain, measured by the items "combing your hair," and "pulling your hair back"; and the mechanical static domain, measured by the items "wearing eyeglasses," "wearing contact lenses," "wearing earrings," "wearing a necklace" and "wearing tight clothing." The Brazilian version of the ASC-12 (ASC-12/Brazil) applied in this study kept all the criteria of the original, and presents an excellent reliability ${ }^{15}$.

\section{Statistical analysis}

Descriptive analysis and percentages were used to characterize the sample and summarize cutaneous allodynia characteristics. Comparison between groups regarding the severity of cutaneous allodynia were made using the chi-square test.

The prevalence ratio, considering allodynia as the outcome, was analyzed through Poisson regression with robust variance, to verify the risk of chronic migraine presenting with the symptom as opposed to episodic migraine. Similarly, prevalence ratios considering the severity of cutaneous allodynia were analyzed using a separate Poisson regression with robust variance. Finally, the prevalence ratio was adjusted for duration of headache in order to verify the risk of chronic migraine sufferers presenting with cutaneous allodynia, and its severity, in comparison with the episodic migraine group.

A more detailed description of the items on the ASC-12/Brazil was conducted, using the frequency of positive responses for each item of the questionnaire in both groups. We then established the correlation between the duration of migraine and the ASC-12/Brazil overall score and each of the three domains by using quantile regression. This process allowed for a comparison among medians aided by STATA 11 software ${ }^{16}$. All statistical analyses adopted a level of significance of 0.05 and a confidence interval of $95 \%$ (CI 95\%).

\section{RESULTS}

Table 1 shows the sample's sociodemographic and migraine characteristics. Cutaneous allodynia was observed in 139 out of 160 participants (86.87\%). The prevalence of cutaneous allodynia in the episodic migraine group was $81.3 \%$ and in the chronic migraine group, $92.5 \%(p=0.03)$ (Table 2).

Regarding the severity of cutaneous allodynia, both groups presented with a high percentage of severe cutaneous allodynia: $48.75 \%$ chronic migraine and $40 \%$ episodic migraine (Table 2). However, there were no differences among levels of severity between the groups.

Quantile regression revealed that only the duration of migraine influenced cutaneous allodynia, and its effect was only evident when considering the overall score (0.08; CI95\% 0.01-0.15; $\mathrm{p}=0.03)$

Table 1. Sociodemographic and migraine data of the episodic migraine group and chronic migraine group, percentage, mean and standard deviation.

\begin{tabular}{lcccc}
\hline \multirow{2}{*}{ Variable } & EM & & CM \\
\cline { 2 - 2 } & $(n=80)$ & & $(n=80)$ \\
Female & $91.25 \%$ & & $95 \%$ \\
Age (years) & $36.6( \pm 10.1)$ & & $38.4( \pm 10.2)$ \\
Duration of migraine (years) & $16.5( \pm 11.1)$ & & $20.3( \pm 11.8)$ \\
Frequency (days/month) & $6.48( \pm 3.76)$ & & $23.25( \pm 6.26)$ \\
Duration of attacks (hours) & $19.81( \pm 18,87)^{\star}$ & & $22.57( \pm 19.89) * \star$ \\
\hline EM: episodic migraine; CM: chronic migraine; ${ }^{*} n=71 ;{ }^{* \star} \mathrm{n}=73$.
\end{tabular}

Table 2. Comparison between the episodic migraine group and chronic migraine group with respect to presence and severity of cutaneous allodynia.

\begin{tabular}{lccc}
\hline \multirow{2}{*}{ Classification } & EM & & CM \\
\cline { 2 - 2 } Without allodynia & $(n=80)$ & & $(n=80)$ \\
With allodynia & $15(18.7 \%)$ & & $6(7.5 \%)$ \\
Mild & $65(81.3 \%)$ & & $74(92.5 \%)$ \\
Moderate & $11(13.7 \%)$ & & $13(16.2 \%)$ \\
Severe & $22(27.5 \%)$ & & $22(27.5 \%)$ \\
\hline EM: episodic migraine; CM: chronic migraine; $* 0=0.03$. &
\end{tabular}


Therefore, the raw prevalence ratio (PR) was adjusted for the duration of migraine. Before the adjustment, the chronic migraine group presented with a significant increased risk of association with cutaneous allodynia of $14 \%$ relative to the episodic migraine group ( $\mathrm{PR}=1.14 ; 95 \% \mathrm{CI}=1.01$ to 1.29 ; $\mathrm{p}$-value $=0.04)$. However, this risk is lowered when adjusted for duration of the migraine and without evidence of increase $(\mathrm{PR}=1.12 ; 95 \% \mathrm{CI}=0.99$ to 1.27 ; $\mathrm{p}$-value $=0.06)$.

Comparative analysis between the groups in terms of the presence of cutaneous allodynia revealed a prevalence ratio greater than 1 for all severity classifications. However, there was no evidence that cutaneous allodynia was more associated with the chronic migraine group when the confidence interval was considered, as illustrated in Table 3.

No differences could be demonstrated between the groups regarding the thermal $(\mathrm{p}=0.91)$, mechanical static $(\mathrm{p}=0.50)$ and dynamic domains $(p=0.35)$. In addition, the chronic migraine group displayed a greater mean overall score on the ASC-12/Brazil questionnaire (8.1 - SD \pm 3.9 ) compared with the

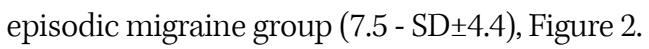

Regarding impaired activities, the chronic migraine group presented with a greater frequency of cutaneous allodynia in

Table 3. Estimates of raw and adjusted prevalence ratios by duration of disease for episodic migraine and chronic migraine groups with regard to presence and severity of cutaneous allodynia.

\begin{tabular}{lcccc}
$\begin{array}{l}\text { Comparison } \\
\text { (CM x EM) }\end{array}$ & PR (CI 95\%) & $p$-value & PR $_{\text {ADJusted }}$ & $p$-value \\
\hline Presence & $1.14(1.01-1.29)$ & $0.04^{\star}$ & $1.12(0.99-1.27)$ & 0.06 \\
Mild & $1.54(0.88-2.67)$ & 0.13 & $1.55(0.87-2.74)$ & 0.14 \\
Moderate & $1.28(0.91-1.79)$ & 0.16 & $1.28(0.92-1.79)$ & 0.15 \\
Severe & $1.24(0.98-1.56)$ & 0.07 & $1.20(0.96-1.51)$ & 0.11 \\
\hline
\end{tabular}

EM: episodic migraine; $\mathrm{CM}$ : chronic migraine; ${ }^{\mathrm{PR}}$ : prevalence ratio with robust variance; ${ }^{*} \mathrm{p}<0.05$. seven out of the 12 items. Among episodic migraine sufferers, the most reported activity was in the thermal domain, while in the chronic migraine group, it was in the mechanical dynamic domain. The frequency of positive response to the item "wearing tight clothing" was $42 \%$ for episodic migraine sufferers and $53.7 \%$ for chronic migraine sufferers indicating that the latter also present with symptoms of extracephalic allodynia (Figure 3).

\section{DISCUSSION}

Our hypothesis that chronic migraine would present with a greater prevalence and worse severity of cutaneous allodynia than episodic migraine cannot be confirmed. The prevalence found was significantly higher in chronic migraine compared to episodic migraine but after adjustment of the years with migraine, no association with increased risk of cutaneous allodynia can be attributed to chronic migraine. Also, the severity of cutaneous allodynia seems to be similar for both according to the ASC-12/Brazil.

The prevalence of cutaneous allodynia observed in episodic migraine $(81.3 \%)$ and chronic migraine $(92.5 \%)$ was greater than that reported by Bigal et al. ${ }^{4}(63.2 \%$ and $68.3 \%$ respectively), which could reflect the difference between samples. Even so, our results are in agreement in terms of a greater prevalence of the symptom in the chronic migraine group.

The greater prevalence of cutaneous allodynia observed in chronic migraine sufferers compared to episodic migraine sufferers could be explained by central sensitization, clinically represented by cutaneous allodynia. Central sensitization is characterized by increased reactivity of the second-order neurons in the spinal cord or the brainstem,

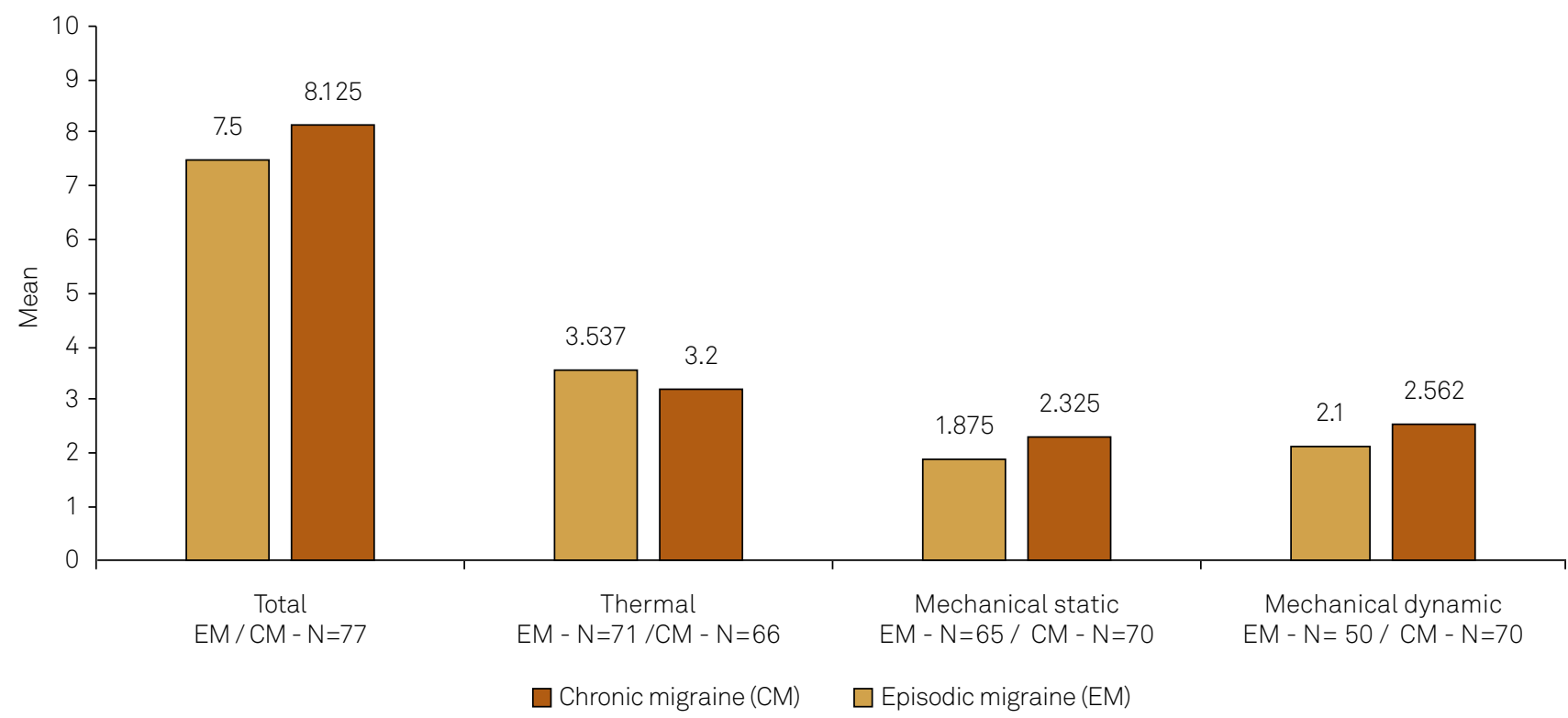

Figure 2. Mean of overall scores and scores for thermal, mechanical static and mechanical dynamic dimensions of the ASC-12/Brazil questionnaire in the episodic migraine and chronic migraine groups. 


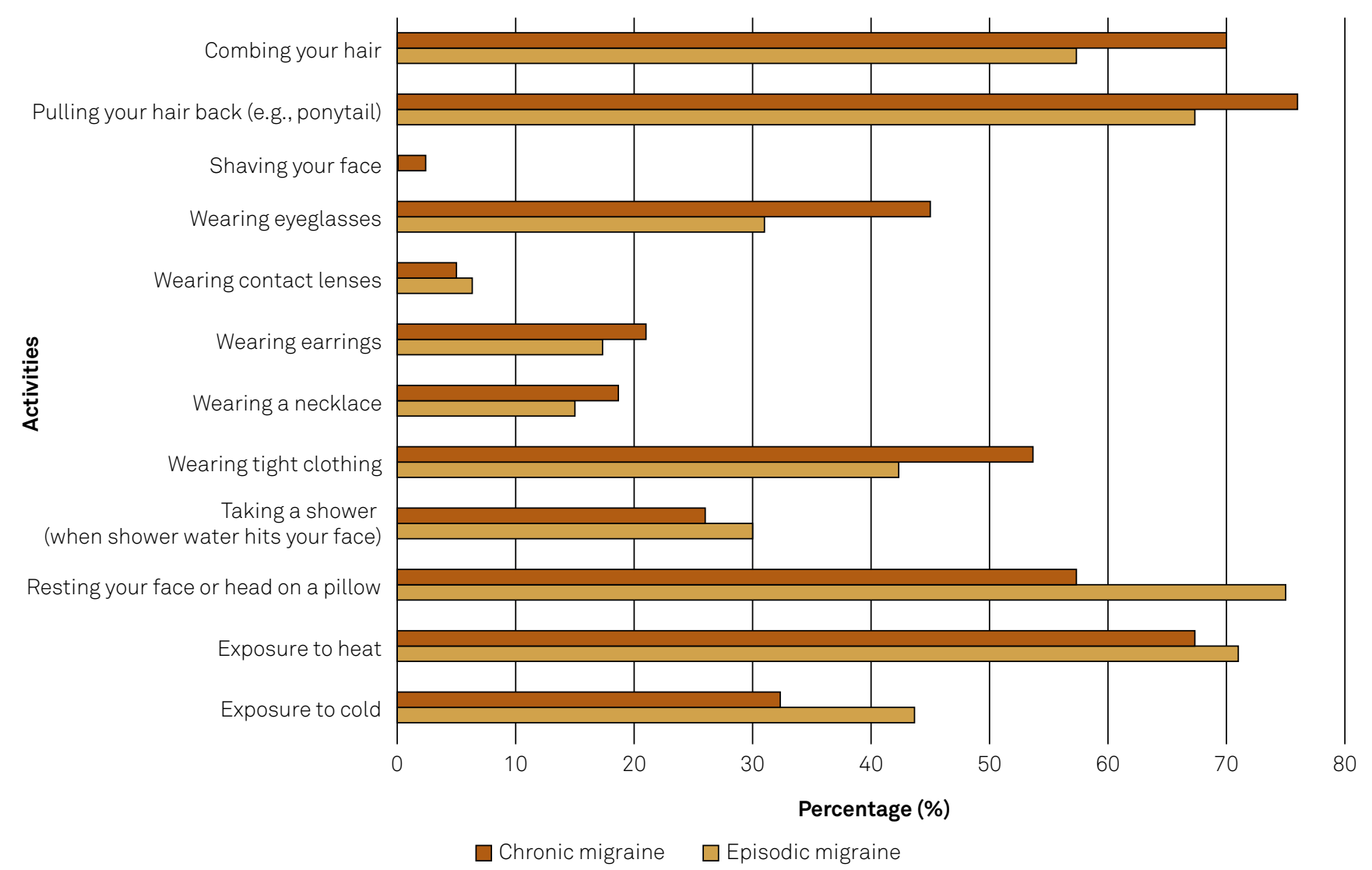

Figure 3. Frequency of positive responses for each item in the episodic migraine and chronic migraine groups.

or of the third-order neurons in the thalamus. In the case of migraine, the trigeminal neurons in the pons (secondorder neurons) become sensitized by the peripheral stimuli from trigeminal neurons of the meninges (first-order neurons), which occurs in each attack. As the trigeminal nucleus in the pons also receives convergent afferent input from the skin of the craniofacial region, this region presents with cutaneous allodynia ${ }^{4,17}$. Therefore, the more headache attacks the patient has, the greater will be the presence of cutaneous allodynia. Our results demonstrated that cutaneous allodynia seems to be more frequent in chronic migraine and is associated with the disease duration. However, our findings reinforce that, when considering the years with migraine, the increased association of the risk of chronic migraine resulting in cutaneous allodynia, compared to episodic migraine patients, is attenuated, as after adjustment no significant difference could be attributed to the prevalence ratio.

In both the episodic migraine and chronic migraine groups, cutaneous allodynia was most commonly classified as severe: $40 \%$ and $48.75 \%$ respectively. However, there were no differences in the proportion of severity between groups. These findings are not in accordance with those of Bigal et al. ${ }^{4}$ due to the differences of the studied samples, but they corroborate those of Schwedt et al. ${ }^{13}$, who also found no differences in the severity of cutaneous allodynia in chronic migraine and episodic migraine patients.
We can infer that the clinical manifestation of cutaneous allodynia between groups is similar, since both groups presented with a higher prevalence for a severe classification and similar distributions between the domains. However, these results do not allow us to say that one group is more sensitized than the other. Instead, we can suggest that individuals with episodic migraine, when cutaneous allodynia is present, exhibit similar clinical allodynia features in relation to chronic individuals, even though the attacks are more sporadic and a lower frequency of cutaneous allodynia is observed. These results do not refute Lipton et al. ${ }^{7}$, since our data demonstrated that individuals with episodic migraine exhibit as much allodynia as chronic migraineurs. Because of this, we should be aware of the risk of these individuals developing a chronic course. In this way, we assume that symptom severity is related to the disease itself and not directly related to the frequency of attacks, since chronic migraine patients presented with a longer period of disease than episodic migraine patients.

An association between the severity and the presence of disease was reinforced by the reduction of the prevalence ratio, which did not show any difference between the groups when adjusted for the duration of disease. Therefore, we concluded that the presence of migraine for long periods is possibly a more significant influencing factor than the monthly frequency of attacks. Our results corroborated those of other studies, showing that the younger patients manifest migraine, 
the more severe the cutaneous allodynia, due to the long period of central sensitization of nociceptive pathways ${ }^{18,19}$.

Regarding frequency of responses for each activity, the distribution of symptoms among domains in both episodic migraine and chronic migraine was balanced. The presence of cutaneous allodynia being associated with all types of stimuli described here coincided with isolated findings regarding thermal, mechanical static and mechanical dynamic domains ${ }^{20,21}$. However, it does not allow us to state that both groups have similar sensitization severity. It only confirms that, when sensitized, they present with similar clinical manifestations. And this is considered the most relevant contribution to migraine knowledge in our study.

Knowing that episodic migraineurs are clinically similar to chronic migraineurs in cutaneous allodynia severity, we should propose strategies to prevent the chronicity of the disease. Therefore, the identification of cutaneous allodynia would help clinicians to offer proper treatment. We draw attention to the frequency of discomfort reported by wearing tight clothing in both groups, $42 \%$ in the episodic migraine group and $53.75 \%$ in the chronic migraine group. We propose that third-order thalamic neurons are sensitized, as clinical manifestations can be observed in extracephalic regions, suggesting a widespread allodynia ${ }^{22}$.

Limitations of this study must be considered. Firstly, although male patients were not excluded, the proportion of them in the sample was very small. It might be a reflection of gender differences regarding the prevalence of migraine as well as differences in the demand for medical care. Therefore, the results described here might be more applied to females. Secondly, the study was performed in a tertiary care unit and results can only be generalized to migraine patients with similar characteristics, such as migraines over a long time and with worse severity. Thirdly, the fluctuation of the frequency of migraine attacks during the past years was not controlled and this can be seen as a limitation, as we could not affirm that episodic migraine patients had never been classified as chronic sufferers. However, the diagnostic criteria considered the frequency of attacks during the previous three months, and this possible limitation concurs with all studies that compare episodic and chronic migraine patients.

In conclusion, the frequency of cutaneous allodynia rises slightly in proportion with an increase in the number of attacks, but its presence and severity seems to be associated with the duration of the disease. Furthermore, no differences of distribution were observed among domains, and both groups were affected similarly in terms of cephalic and extracephalic regions.

\section{Acknowledgments}

Professor José Geraldo Speciali for the patient trial support.

\section{References}

1. Robbins MS, Lipton RB. The epidemiology of primary headache disorders. Semin Neurol. 2010;30(2):107-19. https://doi.org/10.1055/s-0030-1249220

2. Carod-Artal FJ, Irimia P, Ezpeleta D. [Chronic migraine: definition, epidemiology, risk factors and treatment]. Rev Neurol. 2012;54(10):629-37. Spanish.

3. Headache Classification Committee of the International Headache Society. The International Classification of Headache Disorders, 3rd edition (beta version). Cephalalgia. 2013;33(9):629-808. https://doi.org/10.1177/0333102413485658

4. Bigal ME, Ashina S, Burstein R, Reed ML, Buse D, Serrano D et al. Prevalence and characteristics of allodynia in headache sufferers: a population study. Neurology. 2008;70(17):1525-33. https://doi.org/10.1212/01.wnl.0000310645.31020.b1

5. Kalita J, Yadav RK, Misra UK. A comparison of migraine patients with and without allodynia symptoms. Clin J Pain. 2009;25(8):696-8. https://doi.org/10.1097/AJP.0b013e3181b12dd3

6. Tietjen GE, Brandes JL, Peterlin BL, EloffA, Dafer RM, Stein MR et al. Allodynia in migraine: association with comorbid pain conditions. Headache. 2008;49(9):1333-44. https://doi.org/10.1111/j.1526-4610.2009.01521.x

7. Lipton RB, Bigal ME, Ashina S, Burstein R, Silberstein S, Reed ML et al. Cutaneous allodynia in the migraine population. Ann Neurol. 2008;63(2):148-58. https://doi.org/10.1002/ana.21211

8. Burstein R, Yarnitsky D, Goor-Aryeh I, Ransil BJ, Bajwa ZH. An association between migraine and cutaneous allodynia. Ann Neurol. 2000;47(5):614-24. https://doi.org/10.1002/15318249(200005)47:5<614::AID-ANA9>3.0.CO;2-N

9. Jakubowski M, Silberstein S, Ashkenazi A, Burstein R. Can allodynic migraine patients be identified interictally using a questionnaire? Neurology. 2005;65(9):1419-22. https://doi.org/10.1212/01.wnl.0000183358.53939.38
10. Ashkenazi A, Silberstein S, Jakubowski M, Burstein R. Improved identification of allodynic migraine patients using a questionnaire. Cephalalgia. 2007;27(4):325-9. https://doi.org/10.1111/j.1468-2982.2007.01291.x

11. Burstein R, Collins B, Jakubowski M. Defeating migraine pain with triptans: a race against the development of cutaneous allodynia. Ann Neurol. 2004;55(1):19-26. https://doi.org/10.1002/ana.10786

12. Misra UK, Kalita J, Bhoi SK. Allodynia in migraine: clinical observation and role of prophylactic therapy. Clin J Pain. 2013;29(7):577-82. https://doi.org/10.1097/AJP.0b013e31826b130f

13. Schwedt TJ, Krauss MJ, Frey K, Gereau RW 4th. Episodic and chronic migraineurs are hypersensitive to thermal stimuli between migraine attacks. Cephalalgia. 2010;31(1):6-12. https://doi.org/10.1177/0333102410365108

14. Olesen J, Bousser MG, Diener HC, Dodick D, First M, Goadsby PJ et al. New appendix criteria open for a broader concept of chronic migraine. Cephalalgia. 2006;26(6):742-6. https://doi.org/10.1111/j.1468-2982.2006.01172.x

15. Florencio LL, Chaves TC, Branisso LB, Gonçalves MC, Dach F, Speciali JG et al. 12 item allodynia symptom cheklist/ Brasil: cross-cultural adaptation, internal consistency and reproducibility. Arq Neuropsiquiatr. 2012;70(11):852-6. https://doi.org/10.1590/S0004-282X2012001100006

16. Koenker R, Hallock KF. Quantile regression. Cambridge: Cambridge University Press; 2005.

17. Aguggia M. Allodynia and migraine. Neurol Sci. 2012;33(Suppl 1):S9-11. https://doi.org/10.1007/s10072-012-1034-9

18. Güven H, Çilliler AE, Çomoğlu SS. Cutaneous allodynia in patients with episodic migraine. Neurol Sci. 2013;34(8):1397-402. https://doi.org/10.1007/s10072-012-1249-9 
19. Louter MA, Bosker JE, Oosterhout WP, Zwet EW, Zitman FG, Ferrari MD et al. Cutaneous allodynia as a predictor of migraine chronification. Brain. 2013;136(11):3489-96. https://doi.org/10.1093/brain/awt251

20. Kitaj MB, Klink M. Pain thresholds in daily transformed migraine versus episodic migraine headache patients. Headache. 2005;45(8):992-8. https://doi.org/10.1111/j.1526-4610.2005.05179.x
21. Cooke L, Eliasziw M, Becker WJ. Cutaneous allodynia in transformed migraine patients. Headache. 2007;47(4):531-9. https://doi.org/10.1111/j.1526-4610.2006.00717.x

22. Burstein R, Jakubowski M, Garcia-Nicas E, Kainz V, Bajwa Z, Hargreaves R et al. Thalamic sensitization transforms localized pain into widespread allodynia. Ann Neurol. 2010;68(1):81-91. https://doi.org/10.1002/ana.21994 